\title{
Berço de ilusões: o entremeio das criações. Uma reflexão sobre personagens, atores e pessoas
}

I/II/I/III/II Ana Paula Martins Gouveia ${ }^{1}$

1. Pós-doutoranda na Escola de Comunicações e Artes da Universidade de São Paulo, professora na Escola Superior Artística do Porto, em Portugal, e membro do FiloCom, Núcleo de Estudos Filosóficos da Comunicação. E-mail: apaulamg@ig.com.br 
Resumo

Este artigo se propõe a refletir sobre a ligação ontológica entre três instâncias: pessoas, personagens criadas pelo ator e as pessoas ou as personagens criadas durante os nossos sonhos noturnos. Nesse contexto, coloca-se em questão o hermetismo referencial forjado pelos conhecimentos acadêmicos, que, por vezes, podem se tornar um tanto inflexíveis, por uma crença em um conhecimento tido como legítimo, mas que se mostra como efêmero e insuficiente.

\section{Palavras-chave}

personagem, pessoa, criação, realidade, ontologia, legitimidade

Abstract

This article works with the ontological link between three concepts: people, characters created by an actor and people and characters created by us during our nightly dreams. In this context, the question about the hermetic references elaborated by general academic knowledge is raised. These references can, sometimes, become inflexible because of a belief in a specific knowledge taken as legitimate, but that turns out to be ephemeral and insufficient.

\section{Key-words}

character, people, creation, reality, ontology, legitimacy 
2. Ao investigarmos algumas dimensões delimitadas pelo termo ontológico, particularmente entre Aristóteles e Heidegger, fica evidente que qualquer aproximação nesse terreno envolveria um tipo de trabalho que definitivamente não faz parte das prioridades deste artigo. Os cuidados e as ponderações que são necessários para a análise de campos conceituais de tradições filosóficas tão amplas, e muitas vezes bastante distintas, exigiriam uma dedicação específica; além disso, qualquer abordagem feita sem o devido comedimento poderia levar a um esvaziamento dos conceitos com os quais se estaria trabalhando; devido

a tal prudência, optei por utilizar a palavra ontologia em seu sentido primeiro, ligado à origem: ao "o que é”, ao ontos e o logoi, o conhecimento do ser, o berço de onde surgem as pessoas e as personagens.
O ceticismo (...) deveria ter por objeto unicamente as teorias incorretas, e não assestar suas baterias contra fatos comprovadamente certos. Só um observador preconceituoso seria capaz de negá-lo. A resistência contra o reconhecimento de tais fatos provém principalmente da repugnância que as pessoas sentem em admitir uma suposta capacidade sobrenatural inerente à psique (JUNG apud STEIN, 2000, p. 186).

Estas páginas serão dedicadas à reflexão da personagem em sua origem, em sua ontologia ${ }^{2}$, em seu processo de criação anterior a qualquer texto determinado, em busca de uma compreensão mais profunda de aspectos inerentes às nossas próprias criações mentais, antes mesmo de pensarmos na corporalização da personagem de ficção pelo ator.

Deter-se em tal reflexão sobre a personagem parece-me conveniente, uma vez que pode nos levar a um território de investigação não muito explorado, capaz de nos lançar, de nos fazer mergulhar em um terreno movediço, que chacoalha as nossas estruturas e que busca uma dimensão perceptiva que ultrapassa o contexto histórico e a posterior "transformação" de um ator - em que a personagem de ficção estabelece uma relação umbilical com outros seres que criamos quando dormimos ou mesmo conosco como pessoas, a percepção de um eu. Essa expressão organizada em forma de artigo se dedica a proporcionar a reflexão não só sobre um objeto específico mas também sobre algo que possa ir além desse objeto, um questionamento que possa despertar no leitor uma certa inquietação, independentemente da área de pesquisa em que ele atue. Conforme afirmou Klauss Vianna, "a inconsciência é o que gera a medio- 
cridade. O bailarino tem os mesmos problemas de um sapateiro" (VIANNA, 1990, p. 26), a classe de trabalhadores a que pertencemos agora é indiferente, certas questões permeiam todas elas e é sobre essa perspectiva que se escreve aqui.

Para dar início a tal percurso, tomo de empréstimo o pensamento de Anatol Rosenfeld. O autor escreve:

as personagens do espetáculo, apesar da sua concretização sensivel maior do que a do texto, conservam plenamente o caráter de personagens fictícias, em comparação às reais: maior coerência (mesmo quando incoerentes), maior exemplaridade (mesmo quando banais), maior significação e transparência; e maior riqueza - não por ser a personagem mais rica do que a pessoa, e sim devido à concentração, seleção, densidade e estilização do contexto imaginário que reúne os fios dispersos e esfarrapados da realidade num padrão firme e consistente. Por este motivo o fenômeno básico do teatro, a metamorfose do ator em personagem, nunca passa de "representação". O gesto e a voz são reais, são dos atores; mas o que revelam é irreal. O desempenho é real, a ação desempenhada é irreal. Por mais séria que esta seja, a própria seriedade é desempenhada, tendo, pois, caráter lúdico (ROSENFELD, 1969, p. 30).

Atrevo-me então a iniciar um saudável debate e indagar sobre alguns conceitos expostos a partir de tal óptica. Em primeiro lugar, pensaremos na personagem como ser fictício em sua "coerência", "exemplaridade", "significação"; depois, faremos uma comparação entre personagem fictícia e pessoa, para, então, analisarmos a ligação entre elas e as personagens que criamos durante os nossos sonhos noturnos. Começo por estabelecer um diálogo com o pensamento de Rosenfeld, muito embora a minha percepção sobre o tema da ligação entre as pessoas e as personagens levem-me a uma sugestão distinta da do autor.

\section{A personagem e a pessoa}

A afirmação de que em uma peça de teatro, ou em um filme (posto que estamos pensando nos aspectos de concentração dramática inicialmente apresentados em um texto e posteriormente corpo-
3. Concentramo-nos sobre elas como em momentos de peripeteia que se desdobram em uma temporalidade extensa. A peripeteia é um momento que tem uma importância especial nas ações das personagens de um relato, como ressalta Eduardo Peñuela, citando Victor Burgin: "As the painter of 'histories' had to show in a single instant that which took time to unfold, then that instant had to have a singularly privileged position within the total action. It was therefore recommended that the moment selected by the painter for visualization should be the peripateia, that instant in the course of an action when all things hang in the balance" (BURGIN, 1989, p. 86 apud PEÑUELA, 1999, p. 79).

4. Como, em certo sentido, propõem Bob Wilson em seus estudos sobre a câmera lenta. Ele escreve que o ser humano expressa com excessiva rapidez muitas das emoções que experimenta, a ponto de não se poder percebê-las com clareza (GALIZIA, 1986, p. 45); e por isso estimula o trabalho de ralentar as ações para que essas emoções e até os pensamentos possam ser percebidos. 
5. Seria também conveniente considerar que, em geral, as ideias acerca do que venha a ser uma personagem se centram na visão de um simulacro de pessoa, que aparece na sua configuração corporal completa, e não se leva em conta que uma parte anatômica dessa configuração pode ser, ela só, uma personagem, como é o caso de traços de corporalidade enquadrados em um primeiro plano. Isso também pode ser perspectivado em relação aos movimentos das pessoas: podemos simplesmente no deter à observação das mãos, por exemplo, aos movimentos executados por elas e assim por diante.

6. Sobre a questão da expressividade emotiva, hoje em dia tão trabalhada na área da psicologia, mas também nos próprias análises semióticas, poder-se-ia também resgatar ainda os primeiros estudos de Charles Darwin: "before

physiologists had discovered the astonishing facts that the innermost moods of the mind - love, hate, fear, rage, etc. - together with their outermost manifestations, the muscular contractions of the limbs and face, are in great measure dependent upon the functioning, in appropriate spheres of action, of "chemical messengers"

(DARWIN, 1934, p. 5). ralizados por um ator), as personagens são necessariamente mais concentradas - pois muitas vezes uma vida inteira tem que ser contada em minutos - parece-me algo razoável, mas assumir que isso sempre lhes dê maior coerência (ainda que incoerentes), exemplaridade (mesmo que banais), significação, transparência e riqueza do que as pessoas têm soa um tanto excessivo, visto sob certos paradigmas. Mesmo no quesito de concentração, poderíamos pensar em exemplos como os que notabilizaram o cinema iraniano, e não só ele: em casos em que a dramaturgia se caracteriza pela filmagem de atos cotidianos em um tempo próximo ao tempo cronológico, Chronos, no qual nos acostumamos a basear a nossa vida, a maneira como fomos ensinados a calcular as horas. Nesses exemplos, a perspectiva de tentar retratar uma personagem usando uma série de situações e momentos distintos na vida que refletem suas características é substituída por um simples estar presente, por viver aquele momento previamente selecionado pelo dramaturgo, roteirista mas que, mesmo assim, se distancia da proposta de concentração ligada à escolha de "momentos-chave” — , em que podemos identificar a personalidade daquele ser ficcional a partir de vários indícios espalhados pelo tempo construído de forma não cronológica - a subversão do tempo, como gosta de qualificar o cineasta Beto Brant.

Talvez as personagens de ficção tenham essa aparência de maior riqueza e significação, porque nos detemos com grande atenção na observação delas ${ }^{3}$. Se nos detivéssemos, como experiência, na observação de uma pessoa ao executar uma atividade qualquer de seu cotidiano com a mesma atenção, com a mesma concentração ${ }^{4} \mathrm{com}$ que observarmos uma personagem, acredito que o resultado poderia ser surpreendente, pois efetivamente queremos ver, e não simplesmente reconhecer, um alguém em sua cotidianidade, "podemos conhecer nosso semelhante pelos movimentos que ele executa" (VIANNA, 1990, p. 89)5. Pequenas ações poderiam ganhar uma dimensão raramente atribuída por nós aos atos cotidianos, como a que é dada à cerimônia do chá no Japão. A quantidade de emoções e reações, as características corporais e expressivas calcadas nos movimentos da pessoa observada mostrariam toda uma história de vida que poderia ser observada em personagens de maneira mais explícita, talvez, mas não menos profunda ou exemplar ${ }^{6}$. As atitudes do indivíduo observado revelariam para um observador atento, de forma mais ou menos sutil, todo um leque de sentidos e per- 
cepções como os de uma personagem, ou ainda mais complexos. A simples observação das características físicas do indivíduo, como já se provou em tantos estudos de fisiognomia 7 - tanto em seu aspecto de traços comuns entre indivíduos com características físicas e comportamentos semelhantes entre si, quanto na similitude entre humanos e animais ${ }^{8}$ que também refletem traços da personalidade - , já seria uma fonte de informações valiosa. Como disse certa vez Winston Churchill (1959), cada um é responsável pelo rosto que tem após os 40 anos; isto é, bastaria observar as marcas, a postura, a maneira de falar de uma determinada pessoa, para que automaticamente percebêssemos densidade, exemplaridade etc.

\section{Sociedade do espetáculo}

Para fazer essa reflexão sobre o ponto de vista apresentado por Rosenfeld, parece-me então necessário penetrar no campo do que vem a ser "realidade", posto que o autor contrapõe o "irreal" das ações desempenhadas pela personagem ao "real" das ações das pessoas. Pensemos então na relação entre observados e observadores, isto é, na interdependência entre a pessoa e a sociedade que a cerca, considerando também a percepção de cada um sobre si mesmo, tentando aproximar os dois tipos de ação, da pessoa e da personagem, em seus aspectos de “irrealidade”, e não o contrário.

Comecemos por pensar nas personagens que moldamos 9 através dos nossos discursos, dos nossos gestos, do nosso desempenho dentro da sociedade. Ismail Xavier fornece uma excelente exposição desse quadro ao refletir sobre o jogo da representação e os "dispositivos que articulam o olhar e a cena" para além das artes sobre outras formas de relação com o mundo fora de tais molduras, como as interações e os jogos de poder, de grande incidência em nossa vida ordinária - , constatando que existe "uma nítida onda de teatralização da experiência", já diagnosticada como "sociedade do espetáculo", que divide nossa vida social entre atores e observadores. Parafraseando o autor, ele termina seu parágrafo concluindo que tal sistema amplia seu olhar e o coloca como sujeito que aparentemente "tudo percebe" em face dos espetáculos, recolhendo o que as táticas de ilusão "propõem como um mundo de verdade" (XAVIER, 2003, p. 9-10).
7. Iniciados na Índia e posteriormente levados à China (fazendo parte da medicina chinesa até os dias de hoje), e também estudados no Ocidente desde a Grécia Antiga.

8. Sobre esse aspecto específico entre humanos e animais, Jurgis Baltrušaitis (1983, p. 6-53) oferece um estudo e ilustrações comparativas, que incluem fotos de France-Dimanche e desenhos e pinturas de Leonardo da Vinci, P. Rubens, Charles le Brun, Simonneau le Jeune, Camper, Goethe, Johann Lavater, Roman de Fauvel e G. B. Della Porta, entre outros.

9. Fernando Pessoa nos escreve: "Fiz de mim o que não soube, e o que podia fazer de mim não o fiz. O dominó que vesti era errado. Conheceram-me logo por quem não era e não desmenti, e perdi-me. Quando quis tirar a máscara, estava pregada à cara. Quando a tirei e me vi ao espelho. Já tinha envelhecido." (Pessoa, 2001, p. 365). 
10. Muito embora, como propõe o budismo tibetano, por uma questão de acessibilidade ao que seria a verdade absoluta, que está para além de qualquer conceitualização, além do discurso, foi criado um sistema lógico e epistemológico em que se explora a realidade dentro do que é denominado verdade relativa - nela, através da contemplação do discurso, mas não só, o homem pode atingir níveis meditativos em que tem acesso aos fenômenos tal qual eles são. Ver: SHATARAKSHITA, 2005.
Parece claro que, dentro desse quadro social em que vivemos, qualquer conceito de verdade, ainda que se pensasse em "verdade relativa" - se é que isso existe, pois me parece que algo para ser verdadeiro tem que ser absoluto, qualquer aspecto que viesse a torná-lo relativo, automaticamente, o desproveria de verdade ${ }^{10}$, pelo menos em seu sentido absoluto - , apresenta-se como rarefeito, vazio. $\mathrm{E}$ é partir desse ponto que dou início à reflexão sobre a origem das pessoas, tal qual as entendo.

\section{A pessoa e a personagem}

Vamos pensar que somos algo qualquer. Tomemos como exemplo uma determinada profissão: se acreditarmos que somos um pesquisador, isso nos levará a terminar nossa graduação; depois, começaremos um mestrado, ou entraremos em uma instituição de pesquisa, ou qualquer coisa que o valha. Mas o que efetivamente nos leva a ser pesquisadores? O que nos leva a isso é o fato de acreditarmos que é isso que somos (por um dia, ou em vários dias, ou todos os dias,): isto é, o fato de crermos que somos pesquisadores nos impulsiona a sair da cama, a abrir um livro, ir para um laboratório, ou para o campo de pesquisa, e começar a observar determinados objetos, seres ou temas, a ler, analisar etc. Se a mesma pessoa um dia acreditasse que gostaria de se dedicar às habilidades medicinais, se esforçaria para entrar em uma faculdade de medicina e, depois, em cumprir os compromissos que foram estabelecidos para que tal ofício pudesse ser adequadamente realizado, de acordo com as características de sua época.

Quanto mais acreditamos que somos determinada "coisa”, mais nos empenhamos em fazê-la intensamente; isto é, quanto mais pensamos que somos pesquisadores sérios, ainda no mesmo exemplo, mais nos empenhamos em estar atualizados com o material relacionado às nossas pesquisas, mais nos debruçamos sobre o material que para nós tem um valor que nós mesmos atribuímos, e que é bastante relativo ou pessoal. Tal noção de valor está diretamente ligada à noção de "atribuição de valor", que está inexoravelmente conectada à nossa crença anterior no que somos - no caso, pesquisadores. Assim sendo, quanto mais acreditamos que somos pesquisadores, mais nos empenhamos nesse papel, e isso causa reflexos tanto no resultado do trabalho realizado quanto na realidade externa a esse 
trabalho; isto é, o fato de acreditar que é um pesquisador e de se empenhar em realizar o trabalho que é designado para tal opção, em geral, faz que os frutos desse empenho se tornem visíveis para os observadores que têm contato com o trabalho (em outros termos, a sociedade que nos envolve e que se expôs para ter acesso a esses trabalhos). O fato de acreditarmos fortemente que somos pesquisadores e nos empenharmos em realizar esse trabalho com maior dedicação diretamente influencia a "plateia" que observa os resultados: além de nós mesmos nos considerarmos "bons ou maus" pesquisadores, o "público" também o faz, de acordo com as circunstâncias momentâneas que caracterizam esse processo e que também estabelecem critérios valorativos em cada época.

Dentro de tal perspectiva, somente somos pesquisadores, como foi dito acima, porque acreditamos que o somos. Se perdêssemos a memória, por exemplo, e não fossemos capazes de nos lembrar quem éramos e, em um dado momento, começássemos a executar uma outra função qualquer para sobreviver, passado algum tempo, caso a memória da nossa crença em sermos pesquisadores e a das respectivas habilidades não fossem recuperadas, a mesma pessoa se tornaria outra coisa, pois não há nada que intrinsecamente a torne uma pesquisadora - simplesmente o fato de ter se dedicado a isso, assim como se dedicará à nova profissão que acreditará ter após a perda da memória. Assim sendo, intrinsecamente, parece não haver grandes distinções entre o ator que temporariamente acredita - ou não, dependendo da "linha de trabalho de atuação" em que esteja empenhado - "ser" sua personagem, e nós, que acreditamos que somos pesquisadores. $\mathrm{O}$ fato de determinada pessoa ter acreditado que seria um ator levou-a a criar as condições adequadas para poder exercer tal ofício. Assim como acontece com a personagem a ser interpretada, o ator tem que criar uma série de condições para que "tal sujeito adquira vida", e isso, dentro da lógica proposta, faz com que não exista uma diferença ontológica entre a pessoa e a personagem.

Como me parece ter ficado claro, dentro de tal maneira de abordar a "realidade", vista aqui como um "acreditar ser", a noção de "realidade" ou "irrealidade" entre pessoa e personagem é muitíssimo relativa. Assim sendo, qualquer percepção de real ou verdadeiro em tal contexto se torna tênue e, nesses moldes, em que somos formados de acordo com nossas próprias projeções mentais de sermos 
11. Quando se utiliza o termo relativo, pensa-se no sentido de algo que não é absoluto, que depende de outra coisa, que exprime relação; não se faz menção a nenhuma teoria específica, como a de Einstein, ou qualquer outro pensador, pelo menos não neste momento.

12. SARAO, K. T. S. “Anatman/

Atman (No-self/Self)”. In: BUSWELL, R. E. (Ed.). Encyclopedia of Buddhism. New York: Macmillan Reference USA, 2004. (no exemplo dado, pesquisadores), sempre nos encaixaremos em uma construção relativa ${ }^{11}$ da realidade; não se deve deixar de levar em consideração que as nossas propensões em querer desempenhar determinada função dentro da sociedade também são orientadas a partir de certas condições que podem ser explicadas com maior ou menor clareza de acordo com as perspectivas momentâneas de cada ser.

Se pensarmos em um contexto social e econômico, como fizemos ao pensar na sociedade do espetáculo, no Brasil e em outros países, determinadas "classes sociais" parecem ter pouquíssima mobilidade ou, em outras palavras, suas escolhas parecem ser mais restritas à sua situação socioeconômica; outras pessoas, com menos limitações econômicas, a priori, parecem ter mais possibilidades de escolha; de qualquer forma, todos têm que acreditar e se disponibilizar a desempenhar determinada função para que efetivamente possam exercê-la.

\section{Realidade}

Ainda no mesmo exemplo, se a realidade de sermos pesquisadores é relativa, assim como a da personagem também o é, o distanciamento entre pessoa e personagem se torna muito sutil, para não dizer nulo. Mas o que é, foi ou será a realidade absoluta? Tal questão pode ser abordada das mais variadas maneiras. Fico aqui com a perspectiva budista - considerada por Weber (1964) como sendo a única entre as filosofias de orientação também espiritual que não contém falhas lógicas - de que, em termos relativos, "existe" uma natureza pura que permeia todos os seres, mas nossas projeções e nossos hábitos mentais obscurecem tal percepção da natureza intrínseca e não passamos de meros reflexos daquilo que acreditamos ser. Mas se não há nenhum "substrato permanente" (em sânscrito, atman), capaz de dar uma espécie de identidade aos seres, algo que possamos identificar de um momento a outro, de um dia para outro como sendo um "eu", pode-se perguntar como o budismo lida com a questão da existência dos seres humanos, da sua identidade, da sua continuidade e, por fim, dos seus objetivos espirituais ${ }^{12}$. Ao nível da "verdade convencional" (samvrtisatya), o budismo aceita que, no transitório mundo cotidiano, os seres humanos possam ser chamados e reconhecidos como pessoas 
mais ou menos estáveis. Todavia, ao nível da "verdade última" ( $p a-$ ramarthasatya), essa unidade e essa estabilidade de pessoalidade de alguém são apenas uma construção baseada nos sentidos, produto da nossa imaginação. O que Buda encorajou não é a aniquilação do sentimento de "eu", mas a eliminação da crença em um "fantasma nesta engrenagem” que seja permanente, eterno. Assim, o ser humano no budismo é uma criatura concreta, viva, empenhada, e sua personalidade é algo que muda, evolui e cresce. É o humano concreto - não o "eu" transcendental - que finalmente alcança a perfeição pelo esforço constante e pela vontade criativa.

Penetremos então um pouco mais nesse ponto de vista, para evitar que essa perspectiva seja abordada de tal maneira que se assemelhe mais a uma "crença" do que a uma reflexão sobre o assunto tratado, particularmente por abordar uma questão não muito frequente no contexto acadêmico, que é a "ausência do eu", ponto central desta argumentação, e que torna possível a aproximação entre pessoa e personagem, além de envolver outras questões complexas, como a própria morte, a relatividade de qualquer afirmação por via dos conceitos, que será sempre uma perspectiva temporária, e, também, as noções de conhecimento/sabedoria. "Refuto" então possíveis alegações de “inconsistência” por estes três flancos.

\section{Realidade e crença}

Em primeiro lugar, vamos tentar abordar rapidamente o que vem a ser "crença”, que é algo bastante delicado. Pensemos na morte, por exemplo: algumas pessoas acreditam que haja "algo" depois dela, e outras acreditam que não. As que acreditam que sim podem ser divididas em duas categorias. A primeira é formada pelas pessoas que acreditam dentro da relação fiduciária que estabelecem com um outro alguém e, por esse motivo, acreditam em algo após a morte sem experiências pessoais sobre o assunto, mas por confiança. A segunda categoria seria a das que efetivamente se baseiam em experiências pessoais que, por mais que possam ser motivo de descrédito por parte de outros, para elas formam uma "realidade", pois é "experenciada". Essas pessoas, que efetivamente experimentam esse estado de percepção, são também capazes de inspirar os que não vivenciam esse estado, mas confiam nelas. Por outro lado, os que não acreditam em 
13. Tanto texto quanto contexto são termos complexos; não se pode pensar sobre eles como algo semioticamente concluído. Um texto se faz e se refaz a cada nova leitura a que é submetido e, conjuntamente, o seu contexto. Usando uma expressão de

Octavio Paz, um texto trabalha como "signos em rotação", ou ainda como signos em mutação, cujo significado se altera conforme se interage com ele e, consequentemente, com seus também mutáveis contextos. Ver: PAZ, 1996. “algo" após a morte, que a veem como um "destino final” e irrevogável, nunca morreram. De acordo com a sua própria crença, se nunca morreram, como é possível afirmar que não há nada para além daquele momento? Essa crença de que não há nada depois da morte só pode estar calcada em um sistema de valores não comprovados, o que nada mais é do que uma definição de crença.

\section{Realidade e perspectiva}

Em segundo lugar, argumentando que, independentemente do que está sendo pesquisado, e da área de pesquisa, as orientações do pesquisador estarão sempre embasadas em argumentos ou em teorias em que o escritor "acreditou"; as elegeu como sendo as mais pertinentes para moldar e contextualizar as suas perspectivas ou dar estrutura a elas. Assim sendo, qualquer que seja o viés escolhido por quem escreve, ele será sempre uma "crença” deste último, que acreditou que aquela seria a maneira mais adequada para "provar" sua teoria, sua tese, suas hipóteses. O fato de que determinadas correntes de pensamento sejam mais frequentemente usadas como bases "legitimadoras" nos mais variados percursos analíticos não faz com que outras fontes, menos exploradas, careçam de credibilidade.

Quando Bachelard, por exemplo, “dá um pontapé” em uma série de antigos preconceitos que só davam possibilidade de "existência séria" a um determinado tipo de discurso, construído de uma determinada forma, legitimando assim (com toda a sua carga de conhecimento já "comprovada” dentro dos padrões de coerência de conceitos já clássicos) um "novo discurso", que pode se ocupar de fenômenos instantâneos, pedindo que esqueçamos "o antes e o depois" (não querendo dizer com isso que exista texto sem contexto ${ }^{13}$, mas apenas deixando-nos livres para apreensão de um instante verticalizado e poético) e dizendo que devemos nos ater aos momentos em seu presente, ele abre espaço para que mais e mais tipos de discurso possam ser aceitos; o autor escreve:

Um filósofo que formou todo o pensamento atendo-se aos temas fundamentais da filosofia das ciências, que seguiu o mais exatamente possível a linha do racionalismo ativo, a linha do racionalismo cres- 
cente da ciência contemporânea, deve esquecer o seu saber, romper todos os hábitos de pesquisas filosóficas, se quiser estudar os problemas propostos pela imaginação poética. Aqui o passado cultural não conta $^{14}$; o longo trabalho de relacionar e construir pensamentos, trabalho de semanas e meses, é ineficaz. É necessário estar presente, presente à imagem no minuto da imagem: se há uma filosofia da poesia, ela deve nascer e renascer por ocasião de um verso dominante, da adesão total a uma imagem isolada, muito precisamente no êxtase da novidade da imagem (BACHELARD, 1989. P. 1).

Assim como Bachelard, outras áreas do conhecimento se tornam cada vez mais flexíveis, como a linha semiótica que se preocupa com as sensações, com a dimensão tímica das paixões, indo além das raízes lógicas do chamado percurso gerativo. Esses tipos de "abertura" também ampliam os caminhos de percepções das obras, criando condições para que teorias consideradas há pouco como inconciliáveis passem a se imbricar, ainda que mantendo suas especificidades, em pontos que lhe são comuns. Essas perspectivas de abordagem do conhecimento e saber ampliam cada vez mais as possibilidades de discurso, não legitimando apenas uma forma de "expressar conhecimento" e sendo capazes de gerar reflexões inovadoras.

Creio que seja importante alargar cada vez mais as possibilidades dialógicas, no sentido bakhtiniano ${ }^{15}$ do termo - ou intertextuais, se pensarmos em um horizonte analítico mais ligado ao pensamento de Julia Kristeva - , sendo notável que, cada vez mais, ideias provenientes das mais diversas fontes circulam "livremente" no âmbito da academia, fazendo que os paradigmas se renovem constantemente. Além disso, se pensarmos em termos ainda mais abrangentes, voltados para toda a existência humana, podemos recorrer a Carl Jung, que via a tentativa de levar à mente consciente $\mathrm{o}$ arquétipo da imagem de Deus, ou de suas emanações e seus efeitos, como sendo a principal tarefa de toda educação de adultos (STEIN, 2000, p. 216).

\section{Realidade e dimensão do saber e do conhecimento}

Em terceiro lugar, percorrendo os pressupostos teóricos da semiótica tensiva, cito Greimas e Zilberberg, para os quais o saber e o
14. Lembrando que é impossível ao observador desprover-se do seu background perceptivo no ato da observação.

15. Ver: EMERSON, 2003 
16. No Dicionário de semiótica

(GREIMAS \& COURTÉS,

1979, p. 216-217.), encontramos:

"Heurístico (adjetivo):

I. Diz-se que uma hipótese de traba-

lho é heurística se o discurso que a desenvolve tem como efeito produzir

e formular um processo de desco-

berta. É, pois, a hipótese, que não é verdadeira nem falsa, mas anterior ao

estabelecimento do procedimento, que é heurística: os procedimentos de descoberta, uma vez formulados, podem por sua vez facilitar a constituição de novas hipóteses, constituindo

o conjunto a práxis científica.

II. De forma mais geral, qualifica-se

às vezes de heurística uma atitude científica: a abordagem estrutural, por exemplo, que procura em primeiro lugar apreender as relações e obriga, por isso mesmo, a prever as posições eventuais dos termos de uma categoria (termos cujas manifestações não são à primeira vista evidentes) pode, neste sentido, ser denominada heurística”.

17. Houaiss (dicionário eletrônico). Verbete: esotérico: “Adjetivo.

I. diz-se do ensino que, em certas escolas da Grécia antiga, destinado a discípulos particularmente qualificados, completava e aprofundava a doutrina. II. Derivação: por extensão de sentido, diz-se de todo ensinamento ministrado a círculo restrito e fechado de ouvintes.

III. diz-se de ciência, doutrina ou prática fundamentada em conhecimentos de ordem sobrenatural. IV. derivação: sentido figurado. Compreensível apenas por poucos; hermético". conhecimento se distinguem pela profundidade de seu alcance. $\mathrm{O}$ primeiro, o saber, está conectado a um sentido mais hermético e diretamente ligado a uma verdade última e ilimitada; e o segundo, o conhecimento, a um tipo de aquisição de informação, como o das pesquisas acadêmicas - que, por mais profundas e competentes que sejam, se encontram em extratos, em geral, menos profundos na aproximação com uma possível realidade, ou seja, se encontram necessariamente moldadas pela verdade relativa. Zilberberg divide os discursos, enquanto objetos de análise, em três tipologias básicas: o crer, o conhecer e o saber; ele escreve:

O crer é uma das sequências de um complexo discursivo que compreende também o conhecer e o saber: conhecer + saber + crer. Situamos o conhecer num espaço cognitivo onde um sujeito, modalizado pela curiosidade e a atenção, e que se atribui ou a quem é atribuída certa perspicácia, dispõe-se a "penetrar" um objeto que considera - ou que é considerado - como misterioso e mal conhecido. Do ponto de vista discursivo, esse sujeito, ao cabo de sua investigação, acrescenta ou retira um predicado $p$, ou então substitui o predicado p por um predicado p'. O saber, por sua vez, depende da acessibilidade desse conhecimento e, por conseguinte, das interdições ou facilidades que o sujeito encontrará: o enunciado a que o conhecimento chegou será protegido ou revelado? Por fim, o crer, que com razão foi identificado a um "ter por verdadeiro", acrescenta ou não um valor de verdade cuja base é fiduciária. A partir disso, uma tipologia dos discursos deveria se empenhar em reconhecer, num discurso-objeto, o jogo dos componentes respectivamente heurístico ${ }^{16}$ (conhecer), esotérico ${ }^{17}$ (saber) e fiduciário (crer) (FONTANILLE \& ZILBERBERG, 2001. p. 265-266).

Dentro desta perspectiva, podemos pensar no saber diretamente conectado ao esoterismo, que, conforme a definição citada, tem como primeiro significado uma atitude doutrinária, pedagógica ou sectária, segundo a qual certos conhecimentos não podem ou não devem ser vulgarizados, mas comunicados a um pequeno número de iniciados. Muito embora isto não esteja exatamente de acordo com a descrição - pois parece colocar uma "aura de mistérios" em algo que se propõe a, justamente, "remover os véus de obscurecimento" - , podemos inferir que ter acesso a significados até então 
inconscientes ${ }^{18}$ da realidade proveniente de tal saber, que faz parte de algumas perspectivas, pode ser de grande utilidade para uma pesquisa mais verticalizada sobre determinado objeto de estudo. Como disse certa vez Victor Hugo, o ceticismo é a cárie da inteligência, e se, como foi discutido anteriormente, de uma forma ou de outra, somos todos "crentes", por que então desconsiderar filosofias que possam ter conexões profundas com as capacidades "naturais" 19 (jogando com o termo empregado por Jung na epígrafe inicial do trabalho) inerentes à nossa psique?

Muito embora não se esteja fazendo nenhuma espécie de abordagem psicológica, ou filosófica do tema aqui tratado, isto é, o trabalho de ator - busco apenas penetrar no território de nossas projeções mentais e, a partir daí, pensar em uma dimensão pouco consciente, ou totalmente inconsciente (em alguns casos), da nossa interdependência com um todo mais abrangente do que os nossos limitados corpos, pensamentos e emoções - considero importante, dentro de um contexto acadêmico, tomarmos de empréstimo diversas perspectivas, até mesmo em campos pouquíssimo explorados, mas capazes de trazer novas "luzes", ou insights, às investigações - como a teosofia, que, muito embora se distancie das inclinações pessoais de quem aqui escreve, não precisa ser desprezada; acredito que possa ser vista como qualquer outra teoria, que deve ser investigada para que depois possamos questioná-la, citá-la, como qualquer outra área do conhecimento.

Podemos notar que essa dimensão do conhecimento humano, considerada por alguns como transcendental - não no sentido kantiano ${ }^{20}-$, ou mesmo metafísica, faz parte das "raízes" da humanidade e, ainda que não seja necessário ter qualquer tipo de crença religiosa, ou qualquer tipo de conexão com determinada filosofia (ou afeição por ela), desconsiderar tais orientações por mero preconceito, ou pela simples falta de hábito, seria como estagnar o desenvolvimento de um saber de grande potencialidade; muito embora, como foi dito antes, cada um usará aquilo que lhe for mais conveniente.

Jean Cocteau (1985) certa vez escreveu que as pessoas preferem reconhecer que conhecer. Isso talvez lhes dê uma certa sensação de permanência, de segurança, mas lhes deixa muito pouca ousadia. Toda essa limitação é sustentada em nome de quê? De uma pseudolegitimidade? Nietzsche descrevia o homem nesta aventura da
18. Aqui também temos um termo bastante difícil de ser utilizado, uma vez que recebe significações diversas conforme a linha de pensamento psicanalítico que se queira seguir; por isso, novamente optei por tratá-lo por seu significado comum, isto é, como não dotado de consciência, sendo que o sentido atribuído ao que venha a ser a consciência também é complexo, e novamente optei por seu sentido literal.

19. Muito embora o termo utilizado por Jung seja sobrenatural, acredito que o mais adequado seja natural, uma vez que é inerente a nossa psique. Se é inerente, é simplesmente natural. Muito embora a nossa percepção da realidade que nos cerca seja limitada, isso não quer dizer que uma percepção mais ampla seja sobrenatural: ela é natural, posto que é inerente. $\mathrm{O}$ único obstáculo para percebemos esse "conhecimento desconhecido", usando novamente os conceitos junguianos, é o fato de estarmos excessivamente apegados a conceitos e hábitos que acreditamos serem verdadeiros.

20. Manuel García Morente (1948, p. 254) nos passa uma maneira de “comprender fácilmente el sentido que le da Kant a la palabra trascendental. Para Kant - y esta es la enorme y formidable novedad que trae a la historia del pensamiento idealista el objeto del conocimiento no es un objeto cuya realidad sea en sí y por sí, sino que tiene una realidad, distinta de mi vivencia, ciertamente, pero no en sí y por sí. El objeto tiene una realidad objetiva, cuya objetividad no es lo que es, sino en relación con el sujeto". 
vida como um saltimbanco que caminhava em uma linha estendida entre o homem e o além do homem: “Todos os seres, até agora, criaram algo acima de si mesmos; e vós quereis ser a baixa-mar dessa grande maré cheia e retrogradar ao animal, em vez de superar o homem?" (NIETZSCHE, 1989, p. 29). Se estamos sempre caminhando em uma linha estendida, nossa existência é muito mais efêmera e sujeita a riscos do que, por vezes, queremos admitir; apoiamo-nos em bases como se elas tivessem grande solidez, até que um dia dois aviões são capazes de destruir, em segundos, as duas torres gêmeas nova-iorquinas, símbolos da "estabilidade capitalista", provando a impermanência de todas as coisas de maneira violenta. Muitas pessoas tomam consciência do sofrimento que permeia aquele ato, muitos choram, enquanto outros acreditam estar temporariamente felizes pelo sofrimento alheio. Mas a história provará, como já provou tantas vezes, que tal violência causará também sofrimento para os que se sentem felizes com ela.

Para ilustrar ainda mais a questão da inquestionável impermanência, podemos percorrer a percepção de tragédia tal qual a descreve Raymond Williams ao refletir sobre o pensamento nietzschiano. Citando o filósofo alemão, ele escreve:

"[A tragédia] faz que atinemos com o fato de que tudo o que é gerado deve estar preparado para se deformar com a sua dolorosa dissolução. Ela nos força a olhar fixamente para o horror da existência individual, sem que sejamos transformados em pedra pela visão: um consolo metafísico momentaneamente nos alça acima do turbilhão de fenômenos em constante mudança. Por um breve momento tornamo-nos, nós mesmos, o Ser primordial e experimentamos a sua insaciável fome de existência. Agora vemos a luta, a dor, a destruição de aparências como necessária, por causa da constante proliferação de formas pressionando em direção à vida, por causa da extravagante fecundidade da vontade do mundo (WILLIAMS, 2002, p. 61-62).

Não existe estabilidade ou imutabilidade e, assim como tudo muda, nossos atuais paradigmas, quaisquer que sejam eles, em breve se tornarão obsoletos; por que então dar tanta solidez e credibilidade a eles ignorando outras perspectivas, que talvez passem pelo mesmo processo (mas isso só poderá ser constatado quando forem investigadas). O que é uma descoberta científica senão um novo ângulo 
de percepção, uma sacudidela no alicerce de nossos conceitos, um estalo que nos desperta e amplia os nossos horizontes mentais. Assim como um dia a terra pareceu plana aos homens, um dia ela poderá ser percebida como uma mera projeção mental ${ }^{21}$, e a própria percepção de formas poderá ser muito distinta das nossas possibilidades ou até mesmo da nossa imaginação neste momento. Como afirma Dzigar Kongtrul (2005), não é porque uma coisa funciona que ela tem que ser real, isso é uma mera convenção. Ainda usando a argumentação nietzschiana no contexto da tragédia explorada por Williams:

Desde Sócrates, "o impulso dialético em direção ao conhecimento e ao otimismo científico foi bem-sucedido em desviar a tragédia do seu curso". A tragédia "poderia renascer apenas quando a ciência tivesse finalmente sido levada aos seus limites e, confrontada com seus limites, forçada a renunciar a sua reivindicação de validade universal" (WILLIAMS, 2002, p. 64).

Usando um exemplo poético, Fernando Pessoa, em seu tão aclamado poema "Tabacaria", escreve sobre a efemeridade de todos os escritos, de todas as coisas:

Mas o dono da Tabacaria chegou à porta e ficou à porta

Olho-o com o desconforto da cabeça mal voltada

E com o desconforto da alma mal-entendendo

Ele morrerá e eu morrerei

Ele deixará a tabuleta, eu deixarei os versos

A certa altura morrerá a tabuleta também, e os versos também

Depois de certa altura morrerá a rua onde esteve a tabuleta,

E a língua em que foram escritos os versos

Morrerá depois o planeta gigante em que tudo se deu

Em outros satélites de outros sistemas qualquer coisa como gente

Continuará fazendo coisas como versos e vivendo por baixo de coisas como tabuletas

Sempre uma coisa de fronte da outra,

Sempre uma coisa tão inútil quanto à outra,

Sempre o impossível tão estúpido como o real,

Sempre o mistério do fundo tão certo como o sono de mistério da superfície

Sempre isso ou sempre outra coisa ou

nem uma coisa nem outra (PESSOA, 2001, p. 365).
21. O que, em um certo sentido, pode-se inferir dos discursos já bastante antigos e caros à filosofia ocidental, como o mito da caverna platônico. 
Ele, assim com Jung, era um pesquisador do oculto, como acredito sermos nós: estamos à procura de ver coisas ainda não vistas, isto é, pesquisar o até então oculto. Como tão bem descreve Bachelard, o prazer da faxineira é ver o brilho de uma torneira; a sujeira ocultava o brilho da peça, mas, quando esta é polida, o brilho é descoberto (BACHELARD, 1989). Pesquisar é querer descobrir o brilho das coisas, retirar a sua opacidade. Como escreveu Murilo Mendes de Azevedo:

Fernando Pessoa dominava muitas áreas de conhecimento que os homens ditos eruditos repudiavam como sinal de ignorância e superstição, como Carl Gustav Jung, era um pesquisador do oculto, um mestre no que dizia respeito à alquimia, astrologia, rosa-crucianismo, cabala, maçonaria etc. sentia-se atraído por elas como por um abismo (STEIN, 2000).

Umberto Eco escreve: "O bom de um procedimento científico é que ele nunca faz os outros perderem tempo" (ECO, 1996, p. 24). Esse é objetivo aqui, mas tentando ampliar a percepção do que pode ser considerado relevante - a ponto de não implicar perder tempo, mas sim alargar visões. Voltando à perspectiva junguiana, Murray Stein escreve que ao fim da vida Jung começa a se dedicar de forma cada vez mais intensa aos estudos de ordem mais metafísica, muito embora, assim como eu, o próprio Jung não gostasse dessa qualificação. O pesquisador suíço procura articular um sistema unificado que abrange matéria e espírito e lança uma ponte entre tempo e eternidade através de sua teoria da sincronicidade. Tal teoria abarca uma noção de conhecimento absoluto, que muito se assemelha ao pensamento da pura natureza intrínseca a todos os seres no budismo tibetano. Segundo Stein:

O inconsciente desafia as categorias kantianas de conhecimento e suplanta a consciência no tocante à amplitude do saber possível. Por outras palavras, no inconsciente conhecemos muitas coisas que não sabemos que sabemos. Poderíamos chamar-lhes pensamentos não-pensados ou conhecimentos apriorísticos inconscientes. É esta noção que leva Jung aos limites extremos de suas especulações sobre a unidade da psique e do mundo. Se sabemos coisas que estão além da nossa possibilidade consciente de conhecimento, então também exis- 
te em nós um conhecedor desconhecido, um aspecto da psique que transcende as categorias de tempo e de espaço e está simultaneamente presente aqui e ali (STEIN, 2000. p. 187-188).

\section{Pessoa}

Após ter esclarecido, pelo menos no meu entender, os motivos e as perspectivas que demonstram algumas das razões e também a legitimidade das vias de discurso percorridas até aqui, volto ao que havia despertado a nossa discussão antes de nos empenharmos em que acredito serem excursos também construtivos: a premissa de Rosenfeld de que as ações das personagens de ficção seriam "irreais" em relação à "realidade" das ações das pessoas. Independentemente de qualquer "crença", se pensarmos, como vem sendo proposto, na questão da pessoa em seus aspectos de uma não-realidade - de elementos que se mantêm como constituidores de uma identidade apenas quando olhados sob um patamar relativo e efêmero que, em sua própria natureza infinitamente "tômica" (em oposição ao "atômico", que não pode ser separado em partes), demonstra sua impossibilidade de ser uma entidade única, formadora de uma identidade — , a suposta realidade das ações de um ser assim observado se torna tão "irreal" quanto a de qualquer personagem. Tal ponto de vista pode nos levar a uma forma diferente de ver as pessoas e de perceber a imbricação delas com as criações dramáticas, de maneira distinta das que tenho observado nas tantas páginas que contam histórias sobre a trajetória dos atores, dos diretores, do cinema, do teatro etc.

Por mais que, em geral e por muito tempo, tenhamos nos acostumado a nos referir à noção de pessoa como um conceito relativamente simples, ou de fácil compreensão, sem grandes complexidades, tal conceito é bastante "sofisticado". Esse aspecto de "obviedade assumida" é capaz de, muitas vezes, obscurecer ainda mais as nossas percepções. Se retornarmos a textos clássicos, como é o caso de Marcel Mauss (entre outros) em suas investigações antropológicas, podemos notar que o conceito do que vem a ser uma pessoa já era questionado, não só no que significa ser a "outra pessoa”, ou no que concerne ver e perceber a "outra pessoa”, como fazem as tão acaloradas discussões contemporâneas sobre a alteridade, mas o conceito "pessoa" em si: 
trata-se de nada menos que de vos explicar como uma das categorias do espírito humano - uma dessas ideias que acreditamos inatas - lentamente surgiu e cresceu ao longo dos séculos e através de numerosas vicissitudes, de tal modo que ela ainda é, mesmo hoje, flutuante, delicada, preciosa, e passivel de maior elaboração. É a idéia de "pessoa", a idéia do "eu". Todos a consideram natural, bem definida no fundo da sua própria consciência, perfeitamente equipada no fundo da moral que dela se deduz. Trata-se de substituir essa visão ingênua de sua história e de seu atual valor por uma visão mais precisa (MAUSS, 2003, p. 376).

O autor dá início às suas considerações a partir da análise de alguns sistemas tribais e passa pelo que mais modernamente foi chamado de "sociedade do espetáculo", como havia sido citado nas palavras de Ismail Xavier. Mauss escreve:

O fato é que todos esses índios, os Kwakiutl em particular, instalaram entre eles um sistema social e religioso no qual, numa imensa troca de direitos, de prestações, de bens, de danças, de cerimônias, de privilégios, de posições, as pessoas e os grupos sociais são simultaneamente satisfeitos. Vê-se muito nitidamente como, a partir das classes e dos clãs, ordenam-se as "pessoas humanas", e como, a partir destas, ordenam-se os gestos dos atores num drama. Aqui, todos os atores são teoricamente todos os homens livres. Mas, desta vez, o drama é mais do que estético. É religioso, e ao mesmo tempo cósmico, mitológico, social e pessoal (MAUSS, 2003, p. 376).

O aspecto da satisfação simultânea dos grupos parece-me um tanto complexo, posto que vivemos no "reino do desejo" - a noção de desejo é em si bastante ampla —, em que a constante busca por “algo que não temos" se faz presente, e a satisfação é também uma espécie de desejo nunca realizado. Talvez essa percepção de satisfação "no outro" esteja ligada a certo "romantismo" que tendemos a ter devido à distância em relação aos outros. Para além disso, acredito que uma descrição muito semelhante àquela transcrita acima poderia ser feita ao pensarmos em várias sociedades. De qualquer forma, assim como Mauss, também refletimos sobre o contexto de pessoa em sua "sociabilidade", mas o principal, e que também foi questionado por ele, é o pensar em quem é esse "eu”, essa "pessoa”, essa "individualidade" inalcançável. 


\section{In-betweeness}

Ainda sobre o aspecto específico dessas linhas fronteiriças não delimitadas entre pessoa (que neste momento já teve sua "personalidade" em termos de continuidade e realidade questionada) e personagem, podemos ampliar as perspectivas de elaboração sobre essa conexão ao refletirmos sobre o que Richard Schechner denominou de "in-betweenness" que seria uma espécie de entremeidade. O autor escreve:

Performer training and workshops focus their techniques not on making one person into another but on encouraging the performer to act in-between identities; in this sense, performing is a paradigm of liminality. And what is liminality but literally the "threshold", the space that both separates and joins spaces: the essence of in-betweenness? (SCHECHNER, 1985, p. 295).

Muito embora em Schechner a noção de pessoa não tenha sido explorada como foi feito aqui, se pensarmos na elaboração de uma personagem, corporalizada por uma pessoa de "realidade" estabelecida a partir de percepções de um "acreditar ser", essa entremeidade se torna ainda mais sutil: esses dois "acreditares" se misturam e ganham uma nova dimensão, como um sonho dentro de outro sonho, não como um jogo de espelhos, mas sim como uma miragem condensada, em que pessoa e personagem se unem.

\section{Seres noturnos}

Entrando então no terceiro aspecto a ser aqui considerado, já imbuídos por uma noção ainda movediça do que é “pessoa”, em que pessoa e personagem têm suas bases ontológicas bastante semelhantes, pensarmos então em um outro "tipo" de personagem e pessoa: os seres que criamos durante os sonhos noturnos.

Quando dormimos, a nossa mente cria os mais variados devaneios. Sabemos que tudo aquilo era apenas um sonho ao acordamos, mas, durante o sonho propriamente dito, acreditamos naquilo que ocorre, suamos, podemos ficar cansados, assustados etc. Quando acordamos, olhamos ao nosso redor e todos aqueles seres 
que de alguma maneira poderiam estar nos afligindo, deixando-nos contentes ou causando qualquer tipo de emoção simplesmente desaparecem. Isso não quer dizer que, enquanto estávamos adormecidos, tais sensações não nos causassem estímulos "reais", como pode ser comprovado através de diversas pesquisas fisiológicas. Gaiarsa escreve:

Os movimentos oculares que fazemos durante o sonho (no qual imagens visuais interiores são excepcionalmente nítidas) são exatamente como se estivéssemos olhando estas mesmas coisas do sonho, porém acontecendo no mundo exterior. Estes fatos emergiram dos estudos de fisiologistas sobre o estado do sonho (GAIARSA, 1998, p. 74).

O autor ainda relata que os mesmos músculos que contraímos ao subir uma escada ou para fazer qualquer movimento quando estamos acordados são contraídos quando sonharmos que estamos realizando essas mesmas ações e que a energia despendida durante esse ato é muito similar nas duas situações, isto é, acordados ou dormindo. Assim sendo, não parece ilógico admitir que a realidade relativa na qual estamos imersos quando dormimos seja da mesma natureza daquela em que acreditamos ser pesquisadores quando estamos em vigília. Qual seria a diferença se tivéssemos um sonho com duração de duas horas ou de cem anos se, ao acordarmos, percebêssemos que tudo havia sido um sonho? A duração seria um fator capaz de tornar suas "realidades" diferentes?

Durante um sonho noturno, passamos por diversas situações, por vezes muito similares às nossas sensações diurnas, por vezes bastante distintas. Freud (1969, p. 59-78) escreve que há dois tipos principais de instigador dos sonhos, os estímulos somáticos e as excitações mentais. Essas duas categorias podem ser vistas em quatro aspectos de fontes propiciadoras de sonhos: as excitações sensoriais externas (objetivas), as excitações sensoriais internas (subjetivas), os estímulos somáticos internos (orgânicos) e as fontes de estímulo puramente psíquicas. Se estamos com alguma infecção, por exemplo, os sonhos podem ser estimulados por esse tipo de sensação interna; se ouvimos a água da torneira pingando durante a noite, podemos ter sonhos relacionados à água, enchentes e assim por diante; se estamos apaixonados por alguém, podemos sonhar que essa pessoa nos beija ou nos despreza. Mas, independentemente de qualquer 
situação que se manifeste nos sonhos, se não tivermos qualquer percepção de que estamos sonhando e não formos capazes de reconhecer que estamos dormindo, esses sonhos se tornam tão incontroláveis quando a nossa "realidade" diurna. Durante o dia, não sabemos se vamos ter uma dor de dentes ou se vamos ser abraçados por um "linda donzela", da mesma forma como não temos controle sobre as nossas personagens noturnas, não podemos saber se aquela pessoa por quem estamos enamorados irá nos beijar ou nos dar um tapa no rosto, e isso é similar nas duas situações.

Existe uma série de práticas feitas por alguns iogues que os levam a reconhecer que estão sonhando, ainda em estado de sono e, após esse reconhecimento, são capazes de controlar as situações dos sonhos. Mas se a natureza dos sonhos for considerada similar à natureza de nossas vidas diárias, o que impediria que isso também se tornasse possível durante o dia?

É muito interessante pensarmos o motivo de, durante os nossos sonhos, sermos personagens com características muito similares às que temos durante o dia: aspectos corpóreos similares; muitas vezes, atitudes exatamente idênticas às que temos durante o dia; medos e situações também semelhantes. Mas qual é o motivo de tudo isso? Aquele ser que se manifesta em nossos sonhos, sem qualquer sombra de dúvida, é uma projeção de nossas mentes, que, durante aquele estado, tenta manter uma série de características que atribuímos a nós mesmos durante o dia, mas alguma vez nos perguntamos o porquê de isso acontecer? Por que seria isso algo tão natural? Se estamos sonhando, por que teríamos que ter características semelhantes? Por que não poderíamos ser mais altos, mais magros, mais bonitos, mais inteligentes? Claro que isso por vezes acontece, mas acordamos e dizemos que isso "só ocorre em sonho mesmo". Mas o que será que intrinsecamente une esse personagem que se manifesta durante os nossos sonhos, e que chamamos de "eu" (dizemos: "sonhei que estava em uma praia deserta" e, em nenhum momento, questionamos se aquela personagem mental, naquele momento, era o que chamamos de "eu" durante o dia), à personagem diurna que também chamamos de "eu"? Elas se comportam de certa maneira, têm um determinado aspecto corporal, vivem emoções extremamente similares, mas o que, em sua natureza, faz com que uma seja tão diferente da outra? Podemos dizer, é obvio, que durante o dia eu sou "eu”, uma pessoa e que à noite sou 
apenas uma projeção mental desse "eu”. Mas quando, tal qual foi proposto acima, começarmos a questionar o que esse "eu" realmente significa e o que "pessoa" realmente significa, seriam essas duas criaturas tão distintas?

Se pensarmos ainda na questão da personagem que, como parece claro para nós, nada mais é do que um ser ficcional que pode vir a ser incorporado por um ator - que temporariamente alarga seus limites, e pessoa e personagem se entremeiam - não seria essa personagem noturna também um entremeio entre uma série de características que acreditamos ter durante o dia e que projetamos em uma dimensão menos "palpável”, como é a "realidade" dos sonhos, à noite?

Qual é a "verdadeira natureza" dessas personagens noturnas que chamamos de "eu" quando acordamos? E por que elas seriam tão diferentes das personagens diurnas que também chamamos de "eu" quando acreditamos estar acordados? Não seriam essas três instâncias, pessoas, personagens e seres noturnos, muito similares, depois de já termos proposto a relativização desses conceitos? O que ontologicamente as distingue?

\section{Algumas considerações}

Se vivemos em um sistema de crenças que nos leva a acreditar nos fenômenos que nos cercam como uma realidade única e densa, será mesmo difícil investigar, ou mesmo questionar, um sistema enrijecido de ideias que nos foram passadas por uma sociedade tão enferma? E, calcados nessa crença inflexível, seremos incapazes de efetivamente abrir os olhos para outros olhares? Mas se, em vez disso, formos capazes de pelo menos nos determos por alguns instantes em uma perspectiva quase que diametralmente oposta às iniciais, quem sabe possamos ver a possibilidade de tudo ser um sonho não somente como uma bela metáfora, mas algo que possa efetivamente fazer com que nos relacionemos de forma diferente com as nossas vidas, ao questionarmos, por exemplo, o que efetivamente significa o "eu”. Seria "eu” um corpo mais um conjunto de emoções e pensamentos? Se os pensamentos e a emoção são extremamente transitórios e mesmo o corpo que acreditamos habitar está em constante transformação; se não há nada de permanente em 
nenhuma das características e das constituintes que, ao juntarmos, chamamos de "eu"; como esse "eu" pode ser uma "identidade", uma "entidade", uma "personalidade", um "eu”?

Essas interrogações nada têm de "finais". Não são considerações finais ou conclusões; são simplesmente uma proposta de ver as coisas por um outro "ângulo" e, por isso, gostaria de deixá-las "bem abertas". Seria não acreditar em um "eu permanente" uma "grande loucura"? Ou o contrário? Ou seja, saber que o que chamamos de constituintes de "eu" não passa de elementos transitórios e, ainda assim, propor um "eu" mais "real" que uma personagem ou um ser noturno? Não seria isso sim uma "grande loucura"?

Como escreveu Foucault (1997), quando olhamos um consultório psiquiátrico do lado de fora, não podemos saber quem é o louco ou quem é o psiquiatra. Costumamos ser arrogantes o suficiente para achar que "os outros" são os loucos; ou deprimidos o suficiente para achar que "os outros" têm a razão, e que o problema está em nós. Mas quem seria o "grande juiz" capaz de dar um veredicto final? Acredito que apenas uma investigação sincera e profunda sobre a natureza das coisas é capaz de trazer algumas respostas, ou talvez simplesmente mais perguntas, mas ainda assim frutos de um questionar saudável, e não de uma acomodação sedentária sobre já consagrados ou mesmo profanos conhecimentos.

Citamos Foucault, Freud e tantos outros, concordamos ou discordamos deles, mas temos uma certa sensação de estarmos pisando em uma espécie de terreno seguro, pois estamos dialogando com "eus" /"outros" já estruturados dentro de uma lógica ocidental quase que pré-moldada. Não que não seja a favor deste tipo de argumentação. Ao pisarmos em solos que, de alguma forma, nos dão a sensação de andarmos para a frente, podemos sentir alguma estabilidade para, quem sabe, sermos capazes de dar passos ainda maiores. Mas isso não quer dizer que "outros passos" e "outros territórios" sejam menos capazes de nos ajudar a caminhar. E abro então esta última questão: Mas quem é esse "eu" personagem e sonho que caminha? 


\section{Referências}

BACHELARD, G. A poética do espaço. São Paulo:

Martins Fontes, 1989.

BALTRUŠAITIS, J. Aberrations: essai sur la légende des formes.

Paris: Flammarion, 1983.

BLAVATSKY, H. P. A voz do silêncio. São Paulo: Ground, 2002.

BURGIN, V. Diderot, Barthes, Vertigo. In: BURGIN, V.;

DONALD, J.; KAPLAN, C. (Ed.). Formation of fantasy.

New York: Routledge, 1989.

BUSWELL, R. E. (Ed.). Encyclopedia of Buddhism.

New York: Macmillan Reference USA, 2004.

CHURCHILL, W. S. Memórias da Segunda Guerra Mundial.

Rio de Janeiro: Nova Fronteira, 1959.

COCTEAU, J. Ópio, diário de uma desintoxicação.

São Paulo: Brasiliense, 1985 .

DARWIN, C. The expression of the emotions in man and animals.

London: Watts, 1934 .

ECO, U. Como se faz uma tese. São Paulo: Perspectiva. 1996.

. Sobre o espelho e outros ensaios. Rio de Janeiro:

Nova Fronteira, 1989.

EMERSON, C. Os 100 primeiros anos de Mikhail Bakhtin.

Rio de Janeiro: Difel, 2003.

FONTANILLE, J.; ZILBERBERG, C. Tensão e significação.

São Paulo: Humanitas, 2001.

FOUCAULT, M. A história da loucura na idade clássica.

São Paulo: Perspectiva, 1997.

FREUD, S. A interpretação dos sonhos (primeira parte).

Rio de Janeiro: Imago, 1969.

GAIARSA, J. A. O que é corpo. São Paulo: Brasiliense, 1998.

GALIZIA, L. R. Os processos criativos de Robert Wilson.

São Paulo: Perspectiva, 1986.

GREIMAS, A. J.; COURTÉS, J. Dicionário de semiótica.

São Paulo: Cultrix, 1979.

KONGTRUL, D. It is up to you: The practice of self-reflection on

the Buddhist path. Boston; London: Shambhala, 2005.

MAUSS, M. Sociologia e antropologia. São Paulo: Cosac Naify, 2003.

MORENTE, M. G. Lecciones preliminares de filosofía.

Buenos Aires: Losada, 1948. 
NIETZSCHE, F. W. Assim falou Zaratustra: um livro para todos e para ninguém. Rio de Janeiro: Bertrand, 1989.

PAZ, O. Signos em rotação. São Paulo: Perspectiva, 1996.

PEÑUELA, C. E. "La metáfora visual en las cartografias del cuerpo".

Revista Significação, São Paulo, Annablume, n. 13, 1999.

PESSOA, F. Obra poética. Rio de Janeiro: Nova Aguilar, 2001.

ROSENFELD, A. Texto/contexto. São Paulo: Perspectiva, 1969.

SCHECHNER, R. Between theater \& anthropology.

Philadelphia: University of Pennsylvania Press, 1985.

SHANTARAKSHITA. The adornment of the middle way.

Boston; London: Shambhala, 2005.

STEIN, M. Jung: o mapa da alma. São Paulo: Cultrix, 2000.

VIANNA, K. A dança. São Paulo: Siciliano, 1990.

WEBER, M. The sociology of religion. Boston: Beacon Press, 1964.

WILLIAMS, R. Tragédia moderna. São Paulo: Cosac Naify, 2002.

XAVIER, I. O olhar e a cena. São Paulo: Cosac Naify, 2 